\title{
Alexander of Aphrodisias on Pleasure and Pain in Aristotle ${ }^{1}$
}

\author{
Wei Cheng
}

\section{$1 \quad$ Introduction}

The nature of pleasure and its role in human psychology and ethics attracted many early Greek philosophers such as Prodicus and Democritus, and then engaged almost all of the best minds of the Platonic Academy, sparking a series of intense intra-school debates. In these debates Aristotle's understanding of pleasure has a particularly noteworthy and extraordinary status. In contrast to Plato, subsequent Platonists, and the early Greek tradition as a whole, which associate pleasure with a restorative process, the satisfaction of desire, or the quality of our positive affect, ${ }^{2}$ Aristotle offers an energeia-based definition of pleasure, which connects pleasure with the exercise (energeia) of our natural faculty in its good condition, a goal-immanent and self-realized activity.

There are, however, two distinct treatments of pleasure in the Nicomachean Ethics, each of which seems to describe the way in which pleasure is connected with energeia differently. While according to Book VII, pleasure is

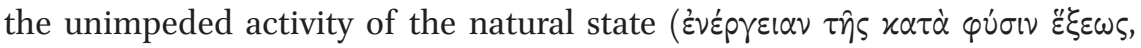
$E N$ viI.12.1153a14), in Book x Aristotle maintains the following:

Pleasure completes the activity. But the way in which pleasure completes the activity is not the way in which the perceptible object and the perceptual capacity complete it when they are both excellent-just

1 I would like to thank audiences at the Humboldt-Universität zu Berlin and Columbia University. For the comments on earlier drafts, I am indebted to Philip van der Eijk, David Merry, Tianqin Ge, Oliver Overwien, and Elizabeth Asmis. I owe special thanks to William Harris for his invaluable proof-reading, advice, and critical remarks. Finally, I am grateful for the support of the Alexander von Humboldt-Stiftung (van der Eijk's research programme: 'Medicine of the Mind, Philosophy of the Body_-Discourses of Health and Well-Being in the Ancient World) that supported me to accomplish my research in Berlin.

2 Here I follow the traditional interpretation of Plato's concept of pleasure, cf. Frede 1997; van Riel 2000: 7-43; Evans 2008; Carpenter 2011. For its reception in later medical tradition, in particular in Galen, see Boudon-Millot in this volume. 
as health and the doctor are not the cause of being healthy in the same way. Pleasure completes the activity not in the same way the state does by being present [in the activity], but as a sort of supervenient end, like maturity on the prime of life.

$$
\text { EN 1174b24-26, b31-33 }{ }^{3}
$$

The account of pleasure in $E N \mathrm{x}$ seems to differ from that in $E N$ VII in one substantial respect, inasmuch as the latter identifies pleasure with a particular activity while the former implies that pleasure and activity are distinct via

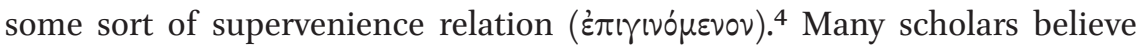
that these two accounts in principle are incompatible. ${ }^{5}$ Moreover, although the majority of scholars are inclined to hold that $E N \mathrm{x}$ offers a philosophically more promising account of pleasure, what persists is widespread disagreement about how to understand the so-called supervenience of pleasure on activity.

In contemporary Aristotelian scholarship we can roughly divide the interpretations of supervenience into two groups. Let us call one the Extrinsic Reading and the other the Intrinsic Reading. The former treats pleasure as an epiphenomenon or a by-product 6 — something that is generated by an activity, but does not exert reciprocal influence on the activity in question. ${ }^{7}$ Inwood, for instance, claims that 'in the Nicomachean Ethics pleasure is not constitutive of the activity which is happiness, but reliably accompanies it. What

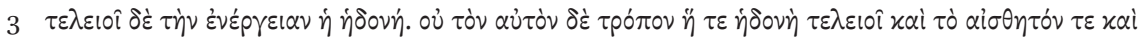

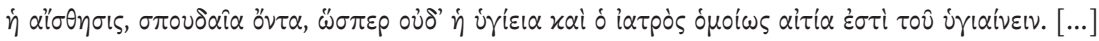

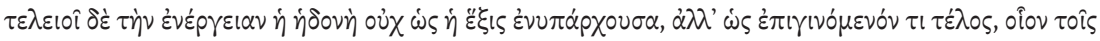

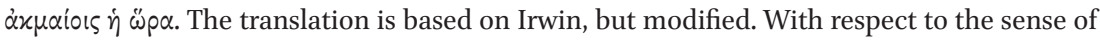

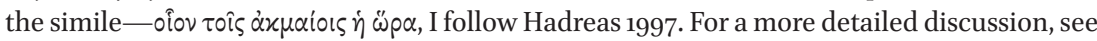
Cheng 2015, 332-3. For a recent defence of the traditional reading 'like the bloom on youths,' see Warren 2016.

4 Following the custom of Aristotelian scholarship, I use supervenience and its cognates to refer to the particular relationship between pleasure and activity (energeia), which can be

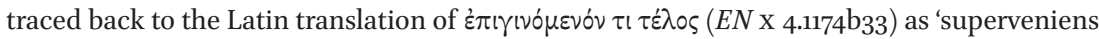
quidam finis' by Robert Grosseteste (cf. Hadreas 1997, 372). Although it is an open question how to specify this relation in Aristotle (cf. Vogt in this volume), certainly it cannot be confused with the term 'supervenience' which is commonly used to characterize a particular dependence of mind on body in contemporary philosophy of mind (cf. Kim 1991). For a discussion of supervenience in Aristotle's philosophy of mind, see Caston 1993.

5 Alexander, PE 143.13-146.12; Festugière 1936; Dirlmeier 1964, 567, 580-1; Lieberg 1958, 7-15; Ricken 1976, 115-17; Gosling and Taylor 1982, 250-4; Wolf 2002, 191, 205; Irwin 2007, 169, n35; Rapp 2009, 222; Heinaman 2011; Shields 2011; Salim 2012; Harte 2014.

6 For the ancient concept of epiphenomenalism see Caston 1997; for this concept in contemporary philosophy see Robinson 2015 .

7 Van Riel 1999; 2000, 43-78. 
motivates us is the drive to activity in accordance with our characteristic rational excellence'. ${ }^{8}$ The Intrinsic Reading, on the contrary, understands pleasure as the perfection of the activity upon which it supervenes. As such, pleasure is constitutive of, and intrinsic to, the activity with which it is connected. Proponents of this reading, however, are not unanimous about how to specify the way in which pleasure makes the activity perfect. Does pleasure function as a final cause, ${ }^{9}$ a formal cause, ${ }^{10}$ the passive dimension of an activity, ${ }^{11}$ or the overall interplay of all excellent aspects? ${ }^{12}$ While the Extrinsic Reading justifies the priority of activity over pleasure by appealing to the ontological dependence of pleasure on activity, which allows for the completeness or perfectness of the activity in question as well as a fixed hierarchy between pleasure and activity, the Intrinsic Reading highlights the constitutive role of pleasure by emphasizing its particular contribution to the perfection of activity.

The dispute between these two readings is still in progress, and perhaps will not end. In what follows, however, I do not want to broach this point of contention directly. Instead, I aim to draw attention to a similar, yet basically ignored debate in antiquity over the obscure relation of supervenience between pleasure and activity in which both Alexander of Aphrodisias and other interpreters of Aristotle, probably his colleagues, students, and even some of his predecessors, took part. ${ }^{13}$ This exegetic debate is hidden in Alexander's

$8 \quad$ Inwood 2014, 40.

9 Cf. Gauthier and Jolif 1958-9 (vol. II.2), 839-42.

10 Gosling and Taylor 1982, 241-54. Taylor $(2008,263)$ has changed his mind, admitting that his early suggestion of pleasure as a formal cause is 'less plausible'. Shields $(2011,207-8)$ suggests that pleasure is first of all an efficient cause, but that it is also a formal and final cause.

11 Salim 2012.

12 Strohl 2011. Strictly speaking, Strohl's position stands somewhere between the Intrinsic and Extrinsic Reading. For he denies that pleasure can function as any of Aristotle's four causes, and qualifies it as a perfect aspect of a well-operative activity. Pleasure is intrinsic to the activity only insofar as it is an ingredient of the excellence of the activity. The excellence of activity $\mathrm{x}$, however, seems to be extrinsic to $\mathrm{x}$ inasmuch as it is added to form $\mathrm{x}$ rather than being an integral part of form $\mathrm{x}$. As the contrast drawn between the minimal condition and the perfection of $\mathrm{x}$ shows, Strohl understands the form of something as the bottom line of what this thing is, a set of basic features shared by all the individuals subordinated to this universal. Yet it is doubtful whether this understanding would be well received by Aristotle, who might be more inclined to take the form of something as an excellent realization of its intrinsic power in a teleological context.

13 This hypothesis does not necessarily commit us to believe that the debates in question happened between Alexander and his opponents in an established institution (as the hedonistic debates among the Academics in the Academy), because (due to the fact that there is no information about any of his immediate pupils) whether and in what sense Alexander had a school is still an open question (cf. Sharples 199ob). Rather, I simply want 
theoretical criticism of some anonymous 'hedonists' in the Problemata Ethica - a collection of short and unsystematic notes about ethical issues. ${ }^{14}$ I shall argue that Alexander develops his anti-hedonistic argument mainly based on the Extrinsic Reading of Aristotle's supervenience-based interpretation of pleasure, whereas the 'hedonists' criticized by him are those who advocate a pleasure-friendly and an Intrinsic Reading of the supervenience in question, or those who try to verify the goodness of pleasure by appealing to Aristotle in this way. In light of this dialogic situation, many of Alexander's argumentative moves are presumably reactions to, and influenced by, the proposal of his opponents who base their theories likewise on a reading of Aristotle.

The reconstruction of this forgotten debate within the Peripatetic tradition is of significance in three respects. First, it provides us a new way to understand Alexander's particular motivation and arguments in his account of Aristotle's pleasure, and in particular several extraordinary features of his interpretation. For instance, it is unusual that Alexander, unlike most Aristotelian scholars, expends so much effort on the clarification and classification of different kinds of pain. Arguably, one motivation for him to flesh out the conception and evaluation of pain is that his anti-hedonistic concern in determining the nature of pleasure - which is presumably initiated by some pleasure-friendly interpretations of Aristotle's theory-leads to a correspondingly friendlier attitude to pain, an opposite of pleasure in his account. This understanding of pain is, however, in tension with the negative evaluation of pain dominant in Aristotle. ${ }^{15}$ Second, since there are only a few incomplete commentaries on Aristotle's Ethics surviving from antiquity, ${ }^{16}$ a reconstruction of this debate

to argue that the main target at which Alexander aimed was the Aristotelian tradition. For my detailed discussion, see below.

14 For discussions of this collection, see Madigan 1987; Sharples 1990a. The collection edited by M. Bonelli: Aristotele e Alessandro di Afrodisia (Questioni etiche e Mantissa): Metodo e oggetto dell'etica peripatetica (Naples, 2015) awaits further examination given that it was published after I finished the main part of my manuscript. As a remedy, I have added a few footnotes to reflect some of the discussions that arose in that volume, in particular the contributions of L. Castelli and C. Natali.

15 Cf. Top. 119a39-b1; EE 1225a16; 1227a 40; EN 1113b1-2; 1385b13-14; Rhet. 1386a7-9.

16 That is the commentary of Aspasius - who is supposed to have lived in the first half of the second century AD-on $E N$ I-IV and on a larger part of EN VII-VIII (in CAG 19.1 ed. by Heylbut). For discussions of this commentary, see Moraux 1984, 226-93; Barnes 1999. A surviving anonymous commentary on EN II-V (CAG 20,122-255, ed. by G. Heylbut) is sometimes believed to have been written later than Aspasius but before Alexander's works (the last quarter of the second century AD according to Moraux 1984, 325; Mercken 1990, 408; or about the late 170s according to Eliasson 2013, 200). The author of this text is taken by Kenny $(1978,37)$ to be Adrastus of Aphrodisias, a Peripatetic active in the 
will provide a valuable slice of the history of the reception of Aristotle's practical philosophy in the ancient commentary tradition, which was overshadowed by extensive works on Aristotle's theoretical philosophy. In particular, it offers us a typical example of the dominant way of doing philosophy from the first century BC onwards, which connects the solution of problems with textual exegesis. ${ }^{17}$ In other words, by virtue of this instance we can see how ancient commentators approach ethics in terms of Aristotelian exegesis, and conversely, how their textual interpretations are deeply influenced by the presupposed philosophical positions. ${ }^{18}$ Finally, as indicated above, the ancient debate between Alexander and other Aristotelians actually foreshadowed the divergence in modern disputes on Aristotle's theory of pleasure. The parallel not only reflects the tension and potential of Aristotle's account itself, but also urges us to reconsider the hermeneutic situation with which we are now faced. If we are not to fall into the stalemate which beset the ancients, Aristotle's notion of supervenience needs to be approached by an alternative proposal which overcomes the opposition between the Intrinsic and Extrinsic Readings.

The structure of my article is the following: to begin with, I show how Alexander interprets Aristotle's doctrines about pleasure, and how his interpretation of these doctrines leads to a particular understanding of pain. After that, I argue that Alexander uses his interpretation of Aristotle to serve his own anti-hedonistic purposes. The hedonism he was most worried about here, however, is neither a vulgar hedonism nor Epicureanism but a pleasure-friendly trend within the Peripatetic tradition, which interprets Aristotle's doctrines of pleasure in such a way as to pave the way for a Peripatetic variety of hedonism. Finally, I shall briefly review the merits and disadvantages of Alexander' approach.

Alexander's discussions of Aristotelian pleasure and pain are chiefly preserved in the so-called Problemata Ethica, a collection of short treatises probably

second century AD, yet it is more likely a compilation that in part depends on Adrastus' work On Historical and Literary Questions in the Nicomachean Ethics of Aristotle (cf. Moraux 1984: 323-9, Mercken 1990, 421-2; also see Barnes 1999, 15-18). For a rehabilitation of its philosophical relevance see Eliasson 2013.

17 E.g. Gottschalk 1987; Sedley 1997.

18 Natali (2015) has recently offered an excellent summary of how Alexander interprets Aristotle's concepts of pleasure and pain by appealing to the principle of Aristoteles ex Aristotele, and to what extent his interpretation is indebted to Aspasius. Nevertheless, the philosophical implication of Alexander's approach is not adequately explored. 
based on his lecture notes, as its subtitle-'school-discussion problems and solutions on ethics' 19 _ indicates. ${ }^{20}$ Although $P E$ is formally structured, like other works in the genre of problemata literature, ${ }^{21}$ by 'question(s) and answer(s)' or by 'thesis and analysis', it is easy to discern that almost all the problems treated here arise from a reading of Aristotle's $E N$, and so the treatises express a strong interest in textual interpretation. The selection of topics in the collection, however, is centered around the pair $\dot{\eta} \delta \circ v \dot{\eta}$ and $\dot{\alpha} \rho \varepsilon \tau \dot{\eta}$, while neglecting many significant subjects in Aristotle's Ethics - which shows the influence of Hellenistic and later philosophical taste. ${ }^{22}$

In accordance with the contemporary mainstream interpretation, Alexander sees no substantial divergence between the two accounts of pleasure in $E N$ VII and $\mathrm{x},{ }^{23}$ but the cornerstone of his understanding of pleasure is $E N \mathrm{x},{ }^{24}$ according to which pleasure is something that supervenes on a perfect activity (energeia) and completes it. ${ }^{25}$ Alexander paraphrases the thought as follows:

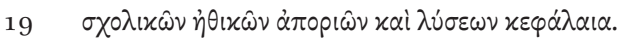

20 We have no compelling reason to deprive Alexander of the authorship of this text, see Sharples 199ob, 1-7.

21 For this genre see Pfeiffer 1968: 69-70; Oikonomopoulou 2013; Taub 2015.

22 The logical and dialectical interests of this text have been correctly highlighted by Sharples (1990a) and Castelli (2015). However, it seems to me exaggerated to claim that in this collection, Alexander's 'interest lies primarily in the theoretical or logical issues rather than in their ethical content as such' (Castelli 2015: 42). It is undeniable that Alexander here is interested in relations of contrariety, predication, and genus/species, and addresses them more frequently than Aristotle did in his ethics, yet this does not mean that 'the domain of ethical concepts becomes a privileged domain for testing and developing formal distinctions' (Castelli ibid.). In this study I aim to show that with respects to pleasure and pain, Alexander's approach and his strategy are essentially motivated by ethical interest and serve ethical proposes, so that many of his arguments cannot be properly understood without his ethical concerns.

23 Cf. Alexander in APr. 302. 5-6, 8-10; in Top. 164. 16-17. A central concern of Problem $\S 23$ (If pleasure is unimpeded activity of a natural state according to Aristotle, how will happi-

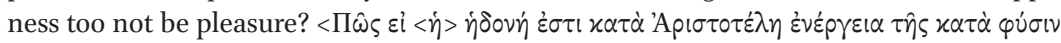

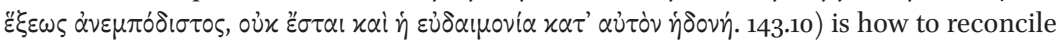
the apparent inconsistence of two different understandings of pleasure in $E N$ VII and x, cf. $P E$ 143. $25^{-144}$. 4. Alexander points out that pleasure is regarded as activity because it always supervenes on activity. This answer suggests that he takes the definition in the $E N$ VII as incautious yet compatible with $E N \mathrm{x}$.

24 Pace Natali $(2015,79)$, according to whom $E N$ viI plays a more important role in Alexander's interpretation.

25 Cf. EN.1174b23; 31-33; 1175a15, 21, 29-30; 35-36; 1175b3o-35. In speaking of the dependence

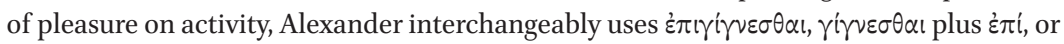
only the preposition $\dot{\varepsilon} \pi \mathrm{i}$. No matter whether Alexander provides a plausible interpretation of Aristotle, I maintain the term 'supervenience' in order to show that Alexander's discussions are substantially based on Aristotle's view in $E N \mathrm{x}$. 
Pleasure follows activities and is in a way a part or an end of them, and it is from them that it has its [worthiness] to be chosen or avoided; for the [pleasures] that [supervene] on activities that are to be chosen are [themselves] to be chosen, and those that [supervene] on those that are not like this are to be avoided.

$P E 127.11-13^{26}$

Readers who are familiar with Aristotle might expect Alexander to specify the supervenience relation between pleasure and activity (energeia). He does not, however, attempt to do this, but seems happy to loosely use different words - following (hepomenē), somehow a part (meros), and an end (telos) to describe this relation at the outset. More surprisingly, he never returns to the whole-part or the process-end relation indicated at the beginning of this passage, but uses the supervenience relation to underline the overall dependence of pleasure on activity. This indicates that Alexander is not so much concerned to clarify the exact nature of the puzzling supervenience, but to justify the ontological priority of activity over pleasure-not only in this passage, but also in this whole collection - by appealing to such a relation. As a result, we cannot recover Alexander's view, if he had one, on how Aristotle thought pleasure played the role of perfection-maker. Alexander's basic idea can be roughly understood as follows:

Given that $\mathrm{x}$ supervenes upon $\mathrm{y}$, any character of $\mathrm{x}$ is determined by a corresponding character of $y$, but not conversely.

In this model, as we have indicated, Alexander's purpose is to foreground the ontological and causal priority of activity over pleasure. As a result, pleasure turns out to be epiphenomenal insofar as the reciprocal contribution of pleasure to the activity with which it is connected is deliberately dismissed. On the basis of this ontological relation, Alexander establishes a corresponding value supervenience, to which he attaches the most weight. According to this, given that a pleasure supervenes on an activity, the pleasure will have the same value as the activity. The pleasure's value is determined by the activity's, but not vice versa. ${ }^{27}$

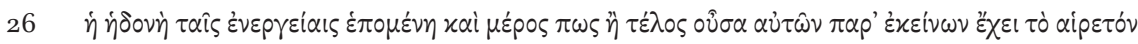

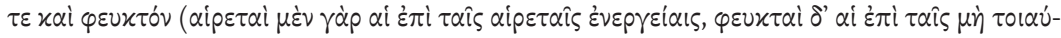
$\tau \alpha \iota \varsigma$. Trans. by Sharples (1990a), modified.

27 PE. 120.11-16; 120.24-31;124.9-11; 18-21; 133.20-23; 134.12-14; 137.1-5; 137.25-27;137.33-36; $146.1-7$. 
This relation explains why some pleasures are good and others bad, by making their value dependent on the value of the activities they depend on. For according to this model, since activities can be good, bad, or neutral, the same goes with their associated pleasures. ${ }^{28}$ It is therefore obvious that neither pleasure as a whole, nor pleasure in the absence of qualifying expression can be qualified as the good or something good. ${ }^{29}$ This conclusion is lucidly expressed by the title of Problem $\S 5$ that if pleasure in general is a genus, it seems neither a good nor an evil nor something intermediate. ${ }^{30}$ As a consequence, it is categorically illegitimate to attribute any evaluative property to pleasure if pleasure is not determined by a quantifying expression.

It is remarkable that Alexander keeps silent about the fact that the activity in question is characterized by Aristotle as perfect or excellent ( $E N 1174$ b16-20). That is, according to Aristotle, pleasure is not simply causally determined by a random activity, but seems to be supervenient upon the activity as long as it is somehow functioning well. Pleasure does not only concur with a good activity, but also shares the same or at least similar characteristics of this activity. It is noteworthy that this extraordinary understanding of pleasure is put forward and gradually fleshed out in a dialectical context in which Aristotle takes issue with his opponents, in particular, the Academics, who define pleasure as a kinēsis or something like kinēsis, which is essentially imperfect according to Aristotle's conceptual schema. Thus, the concept of energeia should be adequately understood in reference to kinessis, and their relation is the key for Aristotle in his attempt to defend the value of pleasure. Alexander, however, diluted the dialectical background in Aristotle's account, ${ }^{31}$ and left the significant opposition between kinēsis and energeia unmentioned. In doing so, he underplayed (if not completely dismissed) Aristotle's normative motivations in making pleasure supervene on the perfect activity, so that he can ignore Aristotle's emphasis on pleasure as the perfection of the activity. A dramatic contrast between the ways in which Aristotle and Alexander utilize the supervenience is that whereas this relation is initially invoked by Aristotle to verify the value of pleasure, Alexander is mainly concerned to resist hedonism in

$28 \quad E N$ 1175a22, 27-28; 1175b1; 1175b 36 ; cf. Alexander $P E$ §3, § 13, § 17; §19.

29 For discussion about the distinction between the propositions with quantifying expression and those without it in Aristotle, see Malink 2015, 273-285.

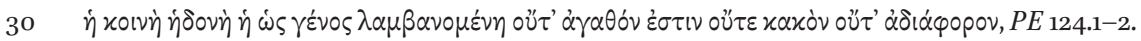

31 This aspect is properly emphasized by Natali $(2015,67$ and 80$)$. Yet he seems to go too far in claiming that Alexander's approach is thus scientific rather than dialectical ('un' indagine scientifica e non dialettica' $(2015,67)$. 
appealing to the same concept of supervenience, which, then, also leads him to an extraordinary understanding of pain. ${ }^{32}$

It is well known that there is no systematic account of pain available in Aristotle's extant corpus. But sometimes he seems to presuppose that pain is a kind of mirror image of pleasure, so that its nature can be inferred from the nature of pleasure. This procedure can be called the 'mirroring method', ${ }^{33}$ which also plays a significant role in Alexander's struggle to evaluate pain: 'for [pleasure] comes about by its affinity to them (sc. energeiai), like a sort of end for them; but pain ${ }^{34}$ is a sign of alienation from the [activities] on which it supervenes' $\left(P E\right.$ 124.29-31). ${ }^{35}$ As in his discussion of pleasure, Alexander does

32 It is extraordinary in the sense that pain, in parallel with pleasure, is understood by a particular supervenience relation between the affect and an energeia (for my more detailed discussion, see below). Ancient mainstream views on pain, however, were dominated by medical thought, in particular, the Hippocratic tradition, according to which pain amounts to some kind of imbalanced state of the body caused by unnatural and violent change (Scullin 2012, also cf. Harris and Boudon-Millot in this volume).

Pace Castelli $(2015,42)$, who seems to suggest that Alexander's interest in the relations between the pairs pleasure/pain and good/bad is determined by his interest in the oppositions of contrariety. I think, on the contrary, that Alexander here addresses these pairs, not because they can be used to illustrate the relations of contraries, but because, in order to offer a proper evaluation of pleasure and pain, he feels it is necessary to struggle with problems concerning different kinds of contraries.

33 The name is owed to Frede (2006, 263).

34 Sharples 1990a consistently translates $\lambda \dot{ } \pi_{\eta} \eta$ as distress and $\pi$ óvos as pain in this collection, which seems to suggest that Alexander more or less follows the Stoic theory of emotion. Although Alexander is doubtless influenced by Stoics in this regard, this choice, however, does not work well for the whole collection for three reasons. First, a main target of Alexander's engagement with pain is to interpret Aristotle. Aristotle does not use $\lambda \dot{u} \pi \eta$ as exclusively emotional, but every kind of pain as well as pain in general or the concept of pain per se. If we follow Sharples, the exegetic feature of Alexander would be obscured. Second, two main concerns of Alexander's handling of this topic are to explain (1) which kind of pain is opposed to pleasure (i்oví), (2) in what sense pain is opposed to pleasure. He does not distinguish between $\chi \alpha \alpha^{\alpha}$ and $\dot{\eta} \delta$ ov $\eta$ in a Stoic way, but is more concerned about the relationship between pleasure and pain as such. Hence even if he draws the distinction between $\lambda \dot{u} \pi \eta$ and $\pi$ óvos in a Stoic way, his motivation is still to solve problems around pain. Finally, and most importantly, Alexander does not have

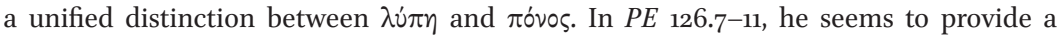
Stoicism-like distinction between $\lambda \dot{v} \pi \eta$ and $\pi$ óvos by referring the former to a contraction of the soul ( $\psi v \chi\llcorner\dot{\nu} v \sigma v \sigma \tau 0 \lambda \dot{\eta} v)$, and the latter to some affliction ( $\theta \lambda \hat{\imath} \psi(v)$ of the body. Nevertheless, in $P E$ 125.32-35, $\lambda \dot{v} \pi \eta$ becomes the general concept of pain, whereas $\pi \dot{v} v 0 \varsigma$ counts as its part. This relation, however, is discussed in $P E$ 127.8-10, in which $\pi$ óvos is taken to be wider than $\lambda \dot{u} \pi \eta$.

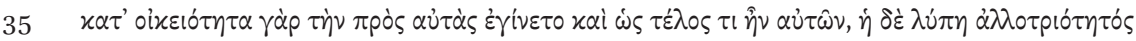

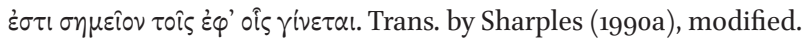


not elaborate on the supervenience of pain, but aims to establish a reversed supervenience of value on this basis:

Similarly it is reasonable to suppose that pains, too, supervening on certain activities, themselves derive from these their worthiness to be chosen or avoided, in the opposite way to the pleasures. For those that supervene on noble activities are to be avoided, those that [supervene] on shameful [activities] are to be chosen.

PE $127.13^{-17^{36}}$

As we can see from this passage, the crucial step for Alexander towards reconstructing an Aristotelian understanding of pain is that pain, in analogy to pleasure, is equally determined as something that supervenes upon energeia. This is by no means a self-evident move, not only because, intuitively, several kinds of pain - for instance, a headache-do not seem to presuppose that I am using my brain, ${ }^{37}$ but also because Aristotle does not explicitly state that the supervenience between pleasure and energeia can be transferred into pain and energeia. ${ }^{38}$

Alexander seem to be aware of these problems. By appealing to the distinction between voluntary, involuntary, and non-voluntary actions in $E N$ III.2, he tries to find concrete examples in Aristotle which show that pain not only supervenes upon energeia, but also does so in an opposite way to the supervenience of pleasure. For according to Aristotle, if someone's bad activity caused by ignorance is afterwards accompanied by pain and regret, this action should be assessed as better than the same action without pain. Pain, then, functions

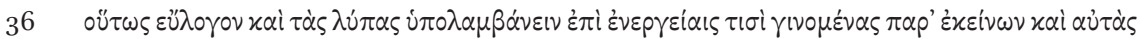

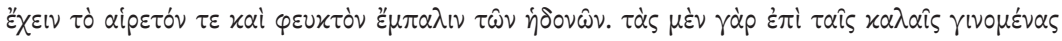

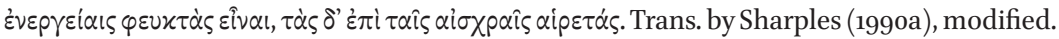

37 Pain of this kind seems to be well explained by ancient medical tradition (cf. Harris and Boudon-Millot in this volume). I leave open whether the same goes with pleasure. Aristotle at least believes that all kinds of pleasure required corresponding activities, but he does not explicitly apply the same thought to pain.

38 Usually Aristotle either takes pain as a hindrance of an on-going energeia (cf. $E N{ }_{1153} \mathrm{~b} 3$ ) or some sort of unnatural change (cf. Resp. 479b26-30; Metaph. 1022b15-21). In DA III.7.431a9-11, however, he seems to classify pain, in parallel with pleasure, under the category of energeia. 'Whenever there is something pleasant or painful, it [the soul] by, so to speak, affirming or denying, pursues or avoids. And it is the case that being pleased and

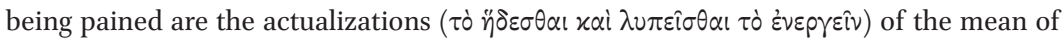
the perceptual faculty in relation to what is good or bad insofar as they are such' (trans. Shields 2016). For a detailed discussion about the sense in which pain can be regarded as an energeia, cf. Cheng 2015, 364-371. 
as a meta-evaluative criterion in distinguishing between involuntary and nonvoluntary activities (cf. EN 1110b19-24; 1111a19-21). Leaving aside whether what Aristotle is saying here instantiates the supervenience in question, if this case represents the supervenience Alexander is focusing on, it would undermine his determination of pleasure and pain as epiphenomena, because the pain seems to be impacting the evaluation of the action rather than the other way round. Whether Alexander is aware of this problem or not, what is more important for him is to find a concrete example in Aristotle which can evidence the reversed supervenience of pain, extrapolated via the mirroring method mentioned above. This relation, contrasted to the label of the supervenience of pleasure as affinity (oikeiotēs) $\left(P E\right.$ 124.29-36), ${ }^{39}$ is called by Alexander an 'alienation' (allotriotês), according to which pains which accompany good activities are bad, pains which accompany bad activities are good, and pains which accompany indifferent activities (epi tais adiaphorois) are indifferent (124.24-26). Based on the notion of pain as an alien supervenience, Alexander establishes a converse value-supervenience of pain, which can be summarized as follows:

Given that a pain supervenes on an activity, the pain will have the opposite value as the activity. The pain's value is determined by the activity's, but not vice versa.

It is remarkable that, just as in the case of pleasure, Alexander does not elaborate how pain supervenes upon activity in an alien way. He is more concerned to establish a systematic evaluation of pain by means of such alien supervenience, which functions perfectly as a counterpart of the supervenience relation between pleasure and activity. Although Aristotle also touches upon alienation, he does not determine pain as an alien supervenience, but only mentions that pleasure derived from activity $\mathrm{x}$ would become painful for someone who is doing $\mathrm{y}$ if $\mathrm{x}$ is alien to $\mathrm{y}$ (cf. $E N \mathrm{x} \cdot 5 \cdot 1175 \mathrm{~b} 1-24)$. No matter whether and

39 The Stoic terms are striking here (cf. Sharples 1990a, 27 n.55). Cf. Chrysippus fr.22ga: ou

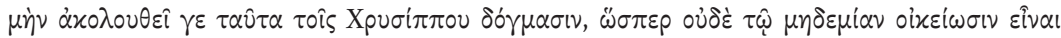

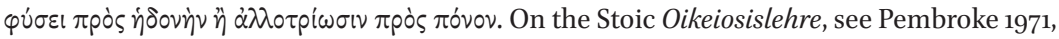
112-49; Engberg-Pedersen 1990; Bees 2004; Forschner 2008. Although it is intricate and controversial how the Oikeiosislehre of the Stoics is related to the Peripathetic tradition (cf. Brink 1956, Szaif 2012, 229-63), it is certain that some early Peripatetics (e.g. Theophrastus, Dicaearchus) propounded some Peripatetic versions of oikeiōsis, which, though impacted by Stoics to varying degrees, can also be somehow traced back to Aristotle's own teaching, cf. $E N$ 1153a20-22; 1175a34-36; 1175b22-23; 1175b16-17; 1175b30-31; 1178a5. 
to what extent Alexander does justice to Aristotle, his approaches have significant consequences.

First, hedonism is false, not because pleasure is bad, but because pleasure and pain cannot provide any non-derived reason or value for actions and choices. Second, even though they relate to activity in opposite ways, pleasure and pain are similar in that pleasures and pains as a whole are essentially indeterminate with respect to their evaluation. ${ }^{40}$ In other words, neither of them is more prone to be good or to be bad. Pleasure as a whole is thus no better than pain as a whole. Third, a broad space is created for the evaluation of pain. This fits well with the Peripatetic preference of proper emotions in which certain kinds of pleasure and pain are blended, yet it is in tension with Aristotle's use in several arguments of the premise that pain is something bad. ${ }^{41}$ The solution of this aporia thus becomes a main task in Alexander's treatment of the nature of pain. ${ }^{42}$

\section{3}

Alexander and the Aristotelian Forms of Hedonism

Alexander addresses the supervenience relation between pleasure and activity as part of a case against hedonism. Aristotle, in contrast, develops the theory of pleasure as standing in a supervenience relation to activity as part of a dialectical defense of the value of pleasure. Prima facie it appears unclear why Alexander, in contrast to Aristotle, is so worried about hedonism. It is reasonable to assume that this feature reflects a widespread hostility towards Epicureanism, which had been a commonplace since the Hellenistic period. Under closer scrutiny, however, Alexander seems to have had a different concern. For what he strives to do is not simply to refute hedonism from a theoretical point of view, but also to 'purify' Aristotle's theory of even the slightest hedonistic hint.

40 Note that the thesis that the value of $\mathrm{x}$ is indeterminate is not equivalent to the thesis that the value of $\mathrm{x}$ is intermediate between good and evil. Rather, it is another way to formulate the thought in Pr. $\$ 5$ that pleasure as a genus seems 'neither a good nor an evil nor something intermediate' (PE 124. 1-2).

$41 \quad E E$ 1225a16; 1227a 40; EN 1113b1-2; Rhet. 1385b13-14; 1386a7-9; Top. 119a39-b1.

42 Pace Natali (2015), who believes that Alexander's main concern in the $P E$ is to verify the thesis that every pain is a bad, yet not every pleasure is a good. This characterization is too simplistic: it fails to pay due attention to the richness and complexity of Alexander's engagement, in particular his struggle with the problem concerning classification and evaluation of pain in terms of the supervenience. 
Like other opponents of Alexander in the $P E$, the friends of pleasure also remain anonymous in his account. It is worth looking at how Alexander characterizes the hedonists in question:

They (sc. the hedonists) are vulgar either because they locate happiness in bodily enjoyments, as do also slaves and cattle, <or $>$ because, according to those, pleasure alone is to be chosen and pain is to be avoided on its own account.

PE $138.8-10^{43}$

In this passage, the hedonists in question are divided into two groups: those who 'locate happiness in bodily enjoyment' and those who take pleasure and pain as the things to be chosen or avoided for their own sake. The former seems to represent a folk hedonism, according to which bodily pleasure is the ultimate good. The position of the latter, in contrast, alludes to a theoretical interest on the estimation of pleasure and pain in activities. It is thus not astonishing that the second group is Alexander's main target in his struggle against hedonism. In another passage, he reports their position in more detail:

For [someone might] say both [1] that only pleasures are to be chosen on their own account, and that each of the other things that are to be chosen [deserves to be chosen] to the extent that it contributes something to pleasure, and also [2] that, while what is noble is to be chosen because it produces pleasure, what is shameful is not also to be chosen because of the pleasure brought about by it.

$$
P E \text { 145.21-25 } 5^{44}
$$

In this outline of hedonism, we can discern few special Epicurean features. For it is not exclusively Epicurean to think that pleasure is worth choosing on its own account. There is little reason on this basis alone to suppose that the Epicureans were the unique target in Alexander's polemic. We should note that the pleasure-friendly tradition was so influential that it is by no means limited to Epicureanism, but was popular in ordinary thinking, and was even endorsed,

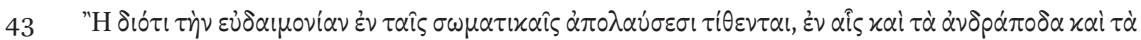

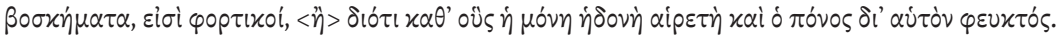
Trans. by Sharples (1990a), modified.

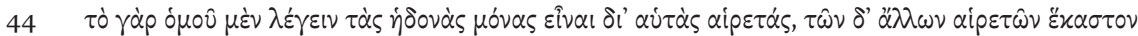

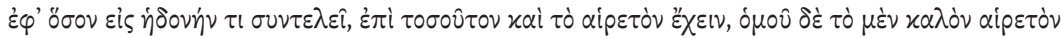

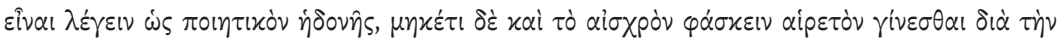

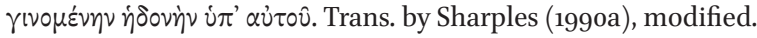


to varying degrees, by several philosophers in other traditions, including Stoics and Peripatetics, who are supposed to have held a serious attitude towards pleasure. ${ }^{45}$ This fact opens up the need to reconsider the complexity of the hedonistic tradition and their argumentative strategies, ${ }^{46}$ which becomes more urgent if we take a look at Alexander's further account of his opponents:

[This person might indeed] say that the pleasures that supervene on noble activities are pure and free from mixture with the opposite pains, and that on this account the activities that produce them, too, are to be chosen; while those [pleasures] that [supervene] on shameful [activities] possess little that gives enjoyment and much and more that produces pains, for which reason such activities too are not to be chosen, being productive of pain rather than of pleasure.

$$
\text { PE } 145.28-33^{47}
$$

It is striking at first glance that Aristotelian jargon and thought can be found in this report, which suggests that Alexander's opponents seem also to be interpreting Aristotle or philosophizing within an Aristotelian framework. ${ }^{48}$ To put it more precisely, they follow Aristotle at least on four points. (1) They understand pleasure as something that supervenes upon activity. (2) They believe that pleasure resembles the activity it accompanies. Concretely speaking, good pleasure always supervenes on good activity, whereas pleasure that accompanies bad activity is shameful, mixed with pains, and thus undesirable.

45 For the traditional image of Stoics as typical anti-hedonists see Vogt elsewhere in this volume. In the intra-school debate, however, Poseidonius and Panaetius are believed to argue against the pleasure-hostile trend of the Stoic tradition by their attempts to defend the value of pleasure, and to incorporate it into the life according to nature (Pohlenz 1940, 6-7). The friends of pleasure among the Peripatetics include Lyco and many others. For my detailed discussion, see below.

46 For a systematic overview of ancient anti-hedonistic arguments, see Vogt in this volume.

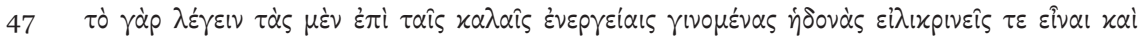

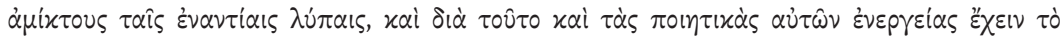

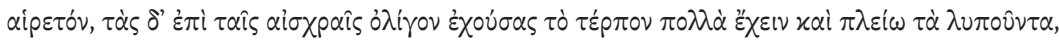

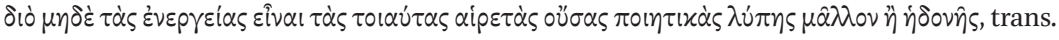
by Sharples (1990a), modified.

48 With respect to the syncretic tendency of different philosophical schools from the Hellenistic time onward, it is of course possible that Alexander engages the view of his opponents in his own (i.e. Aristotelian) terms, so that the Aristotelian features of the hedonists in his report might stem from Alexander himself. It is, however, unlikely in our case, because, as I shall show, the resemblances between the hedonists and Aristotle's account of pleasure are so systematic that it cannot be explained only in terms of the contamination in terminology. 
(3) The pleasure that originates from perfect activity is described by them as pure and removed from mixture with pain, which seems to correspond to Aristotle's concept of pleasure without qualification (haplōs). (4) They not only oppose pleasure to pain, but also hold that bad pleasure would give rise to a corresponding pain. This kind of pleasure seems to belong to pleasure per accidens according to Aristotle. ${ }^{49}$ So far, Alexander's opponents appear very Aristotelian. ${ }^{50}$

Why was Alexander so annoyed by this doctrine that he thought it necessary to refute it? The central anxiety of Alexander is that these people are confused about the hierarchy of pleasure and activity, because according to the theory quoted above, Alexander complains, pleasure would not be worth choosing because of activity, but activity would be valuable because of pleasure. This critique appears a bit odd, since these hedonists seem to agree with Alexander that pleasure and pain supervene upon activities and thus their natures are somehow determined by the activities accompanied by them. For this reason, they do not necessarily belong among the hedonists who believe that only pleasure offers the ultimate or the non-derived reason for motivations and actions. The disparity between Alexander and his opponents is rather that the latter have in mind a different kind of supervenience between pleasure and activity, or that they interpret the Aristotelian supervenience in a different way. Alexander believes that the goodness of pleasure is determined by the goodness of activity, yet he does not think that a good activity must entail pleasure, nor that the concurrent pleasure constitutes the goodness of the activity. According to the 'hedonists,' on the contrary, the activity upon which pleasure supervenes ought to be good in a certain sense. Pleasure is not only causally effective, but also constitutes the value of the activity to which it is connected. Accordingly, Alexander holds that it is possible for pain to supervene upon any kind of activity, whereas the 'hedonists' seem to think that pain only supervenes upon incomplete or bad activities. Presumably they would justify this view by insisting that it is incoherent to claim that pain can supervene upon a perfect activity, because the coexistence of pain must have harmed the activity accompanied and thus undermined its perfection.

If we recall Aristotle's theory of pleasure in $E N \mathrm{x}$-that pleasure is something that supervenes upon an activity and makes it perfect-it is clear that

49 About Aristotle's distinction between pleasure without qualification and per accidens, see

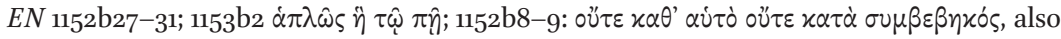
cf. 1153a29-30, 1154b15-20.

5o Sharples' conjecture (1990a, $45^{-6}$, n.142) that they are 'right-thinking people in general, to which some Aristotelians could belong. His suggestion seems to me too broad to grasp the character of these hedonists. 
Alexander takes the asymmetrical relation entailed in the supervenience as the central lesson of Aristotle's definition of pleasure, whereas for the 'hedonists' what is more significant is the role of pleasure as a perfection-maker of a perfect activity. Since the theory of the 'hedonists' operates within Aristotelian philosophy, it is plausible to assume that the 'hedonists' criticized by Alexander are first of all those who stand for another line of interpreting Aristotle's theory of pleasure, or at least those who attempt to defend a pleasure-friendly position in an Aristotelian way. We should not forget that in contemporary Aristotle scholarship there are those who frankly acknowledge the close relation between Aristotle and the hedonistic traditions in later generations. ${ }^{51}$ It is of course possible that a similar reading of Aristotle emerged preceding and contemporary to Alexander. In this sense, as anticipated above, the debate between Alexander and the 'hedonists' not only concerns the problem of whether hedonism is theoretically tenable, but is motivated by the question of which reading is a more authentic interpretation of Aristotle. This result fits well with the general character of the $P E$, which exhibits strong interest in textual exegesis.

Our hypothesis is in accordance with Sharples' general characterization of Alexander's approach-'Alexander's discussions of pleasure, a major concern of the Ethical Problems, are concerned with problems raised by Aristotelian doctrine rather than with specifically anti-Epicurean polemic 52 _and it can also gain support from a broader historical point of view. Intra-school debateswerenotunusual within Greekphilosophical schools, perhapsinparticular among Peripatetics. ${ }^{53} \mathrm{Hahm}$, for instance, has shown how Critolaus (c. 200с. 118 вс) argues against the technicity of rhetoric in favor of the relevance of philosophy to political education, whereas his younger colleague, Aristo of Cos, conversely insists that rhetoric is a science by appealing both to Aristotle and the Academics. ${ }^{54}$ In tune with this tendency, Alexander also has no qualms about criticizing his Peripatetic predecessors such as Andronicus (cf. In APr. 161. 1), Sotion (cf. In Top. 434. 2), and Xenarchus (cf. Mantissa 151. 3-11, Simplicius in Cael. 21. 33), ${ }^{55}$ although he does not always refer to the critical targets by name. ${ }^{56}$

\footnotetext{
$51 \quad$ E.g., Merlan 1960; Hardie 1968, 295; Rorty 1974, 482; Van Riel 2000, 46; Wolfsdorf 2009.

52 Sharples 1990b, 95.

53 Cf. Sedley 1989, 99.

54 Hahm 2007, 54-6o.

55 For Alexander's relations to his predecessors, see Sharples 199ob, 89-90.

56 In Mantissa 106.20-23, for instance, Alexander argues against a literal interpretation of the potential intellect as matter without mentioning Xenarchus, the Aristotelian who is supposed to hold this view (cf. Falcon 2012: 135-138). Sharples (1990b: 88) also assumes
} 
It is especially telling that there was a divergence between pleasure-friendly and pleasure-hostile trends within the Peripatetic school prior to Alexander. Lyco of Troas (c. 299-c. 225 BC), who was the head of the school after Strato c. 269 вс for more than forty years, is representative of the former attitude, because he defines eudaimonia as true pleasure (chara) of the soul accompanying the noble (epi tois kalois, fr. 10 Wehrli). ${ }^{57}$ By contrast, Critolaus of Phaselis, who famously rejects the idea that pleasure can be constitutive for the goal of activities and degrades it as something bad (fr. 23 Wehrli), belongs to the latter group. ${ }^{58}$ The parting of ways among the Peripatetics happened not only for theoretical reasons, but was also probably motivated by issues in the exegesis of Aristotle. ${ }^{59}$ Stephen White has convincingly argued that Lyco's theory comes into dialogue with Stoicism and Epicureanism, ${ }^{60}$ whereas Inwood adds, with good reason, that what Lyco represents is presumably 'a more hedonistic interpretation of Aristotelian ethics.' ${ }^{61}$ Remarkably, the phrase epi tois kalois is resonant with the frequent occurrence of the same phrase in Alexander, ${ }^{62}$ in particular his use of the preposition 'epi' as a shorthand to refer to the supervenience relation in Aristotle's theory of pleasure. ${ }^{63}$ It is not impossible that Lyco

that in $P E \S 11$, Alexander might adopt Aspasius' discussion of the involuntary and voluntary actions (Apasius 59. 2-11), and that it contains a critical reply to Adrastus if the anoymous commentary uses Adrastus' materials on this topic. In any case, Aspasius and Adrastus are not mentioned here.

57 Cf. White 2004, 389-94.

$5^{8}$ For discussions of Critolaus' ethics in historical context, see White 1992, 86-90; Russell 2010, 160-71; Hahm 2007, 62-81; Szaif 2012, 156-67, 184-86.

59 Even if the interpretation of Aristotle did not take pride of place among the earlier Peripatetics as it had done since Antiochus or since the publication of Andronicus' edition, we cannot exclude it from the activities of the Hellenistic Peripatetics (cf. Lefebvre 2016, 28-30). Barnes (1997) has shown that the stories around the revival of Aristotle due to the rediscovery of his 'esoteric works' are more or less exaggerated. For a recent discussion about the reception of Aristotle's ethics in the Hellenistic period, see Nielsen 2015.

$60 \quad$ White 2002, 76-9.

61 Inwood 2014, 39. Although Inwood correctly, in my view, highlights the exegetical context of Lyco's hedonism, I suspect that he goes astray in regarding Lyco's position as 'an attempt to unify Aristotle's two accounts of pleasure and its relationship to happiness' (Inwood 2014, 41). This claim presupposes, indeed as Inwood himself believes, that the accounts in $E N$ VII and $\mathrm{x}$ are actually incompatible, and that the former is advantageous for hedonism, whereas the latter is anti-hedonistic. As Aspasius, Alexander, and many others show, that ancient critics usually do not take the two accounts as contradictory in this way. The Aristotelian hedonists recorded by Alexander are not exceptional. We unambiguously see them freely using $E N \mathrm{x}$ to support their hedonism rather than exclusively insisting on $E N$ VII.

62 Cf. $P E 146.1 ; 152.21$.

63 E.g., $P E$ 126.1, 127.12-13, 137.3-4, 137.7-9, 152.20-23. 
interprets the Aristotelian supervenience relation as if true pleasure is something that is so closely connected with the noble things that it must constitute eudaimonia as its central ingredient. If so, what we encounter is just a hedonistic interpretation of Aristotle's classical theory of pleasure, which resembles the hedonism criticized by Alexander.

This assumption can be further buttressed by another of Alexander's texts, namely a treatise in the collection Mantissa with the title 'From [the teachings of] Aristotle concerning the first appropriate thing' (Mantissa $\$ 17,150-153$ ). ${ }^{64}$ Although there have been several studies of this text, most of them center on the Stoic elements in the Peripatetic arguments, ${ }^{65}$ whereas none of them attaches due weight to the philosophical importance of the intra-school debates over the nature of pleasure implied here. In fact, just as in the $P E$, Alexander also takes this opportunity to attack hedonism in the Mantissa. Yet, unlike in the former case in which Alexander's opponents remain anonymous, here the polemic is unambiguously directed at the hedonists who defend their attitude by appealing to Aristotelian doctrines. ${ }^{66}$ Alexander reports the first group as follows:

Others say that, according to Aristotle ( $\varkappa \alpha \tau \dot{\alpha}$ 'Apı $\sigma 0 \tau \dot{\varepsilon} \lambda \eta)$, the primary

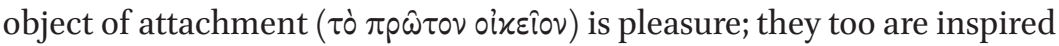

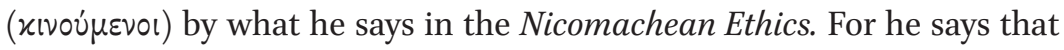

64 I follow the suggestion of Sharples 2004, 149 n. 507. Different translations of the title T $\omega \nu \nu$

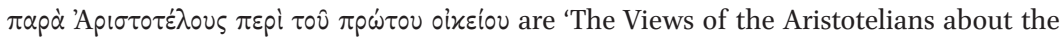
Primary Object of Attachment' (Inwood 2014, 118), '[Selections] from Aristotle concerning the first appropriate thing' (Falcon 2012, 142); 'From the Aristotelian tradition concerning the first appropriate thing' (Sharples 2004, 149; 2008, 206). It is important to see that the

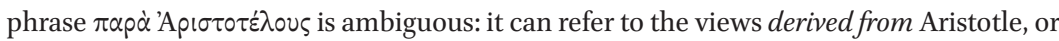
those found in Aristotle. For a discussion of this phrase, see Falcon 2012, 47-8.

65 Cf. Philippson 1932, 460-4; Striker 1997, 282-4; Sharples 2004. 149-59; 2010, 152-4; Falcon 2012, 145-57; Inwood 2014, 118-25.

66 At the beginning of this treatise, the followers of Epicurus ( $\tau 0 \hat{\varsigma} \varsigma \delta \dot{\varepsilon} \pi \varepsilon \rho i^{\prime}$ 'E $\pi$ ixoupov 150.33)

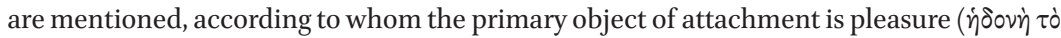

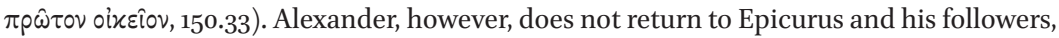
but only addresses two different kinds of hedonistic arguments that are mainly based on Aristotle's theories (151.11-27). Although the 'Aristotelian' hedonists seem to agree with Epicurus in believing that pleasure is the first natural attachment, they do not think that pleasure is differentiated into two kinds: kinetic and katastematic (=freedom from pain) (cf. 150.34). Alexander's move from the Epicureans to the Aristotelian hedonists corresponds to, and is in parallel with, his shift from the Stoics $(150.28-33)$ to the Stoicized Peripatetics Xenarchus and Boethus $\left(151.3^{-11}\right)$ in the same treatise. As in the $P E$, the main interest of this treatise is the intra-school debates, although the question itself-what is the primary object of attachment—manifests a Stoic influence. 


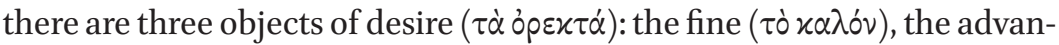
tageous, and the pleasant. And an object of desire is something to which we have an attachment $\left({ }_{i} i \varepsilon \varepsilon i \omega^{\prime} \mu \varepsilon \theta \alpha\right)$. But we come to grasp the noble and the advantageous as we get older, but we grasp the pleasant immediately

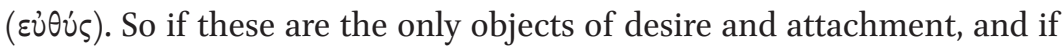
the first of these is the pleasant, then this would be the primary object of attachment.

Mant. $151.18-24^{67}$

In this passage, some Aristotelians attempt to justify their hedonism by arguing that pleasure is the primary object of desire, the ultimate end of life. This argumentative strategy is obviously influenced by the Stoic theory of oikeiosis, yet, as a philosophical fashion since Hellenistic times, the use of this concept is by no means limited to Stoicism but spread widely among different philosophical schools. ${ }^{68}$ In the so-called divisio Carneadea, ${ }^{69}$ for instance, different attitudes towards three natural objects of desire - pleasure, freedom from pain, and the primary natural object (prima naturalia) - function as a guideline for classifying ethical theories. ${ }^{70}$ Of nine different views on the ultimate good listed, the Peripatetics have diverged from each other, holding at least four different positions. ${ }^{71}$ A pleasure-friendly view is espoused by Calliphon and Deinomachus, ${ }^{72}$ who argue that the highest good is a combination of virtues with pleasure, whereas the others opt for the freedom from pain (Hieronymus), the combination of virtue with freedom from pain (Diodorus), and the primary natural object (anonymous). Although the details of the reasons for their divergence cannot be restored, the intellectual milieu has sufficiently manifested the flexibility and multiplicity of the Peripatetic tradition.

In accordance with the para-Stoic tendency, the Aristotelian 'hedonists' in Mantissa 151.18-24 follow the same tactic in their attempt to verify the primacy of pleasure by demonstrating it to be the primary object of desire, yet it is uncertain whether their purpose, as with Calliphon and Deinomachus, was to make pleasure and virtue compatible by integrating both into a unifying concept of the ultimate end, or whether they go further, drawing out a more ambitious hedonistic consequence. It is of course dubious how far these Aristotelians can be taken as 'loyal' to Aristotle. For in their arguments, not

67 Trans. by Inwood (2014), modified.

68 Cf. Trapp 2007, n. 43, with references.

$69 \quad$ For this table see Algra 1997; Leonhardt 1999, 135-212; Annas 2007.

70 It is reported by Antiochus through Piso in Cicero's de Fin. v 16-21.

71 According to Cicero, three of them are only theoretical possibilities, held by nobody.

72 Wehrli et al. 2004, 629; White 2002, 90. 
only are the Aristotelian terms haireta (Top. 118b28; 105a 27) and haireseis (EN 1104b30) replaced by the Stoic term orekta ${ }^{73}$ but the hedonistic argument based on taking pleasure as the direct (euthus) attachment also echoes the classical Stoic strategy in their explanation of the significance of self-preservation as rooted in the primary oikeiosis. ${ }^{74}$ In spite of being tinged by Stoic vocabulary and conception, it is Aristotle who is explicitly invoked by the 'hedonists' as their authority, perhaps not only his classification of the good into the fine, the advantageous, and the pleasant, ${ }^{75}$ but also his ranking of different kinds of ends in $E N$ I. 7-8. It is remarkable that Aristotle claims on one occasion that the good is something of our own (oikeion ti) and hard to take from us (EN 1095b25-27), and he also praises Eudoxus' argument in favor of pleasure as something divine $(E N$ 1101b27-31). Those 'hedonists' seem to read such scattered evidence through the prism of Stoicism, fashioning it into a coherent argument in favor of their pleasure-friendly position. Perhaps it is for this

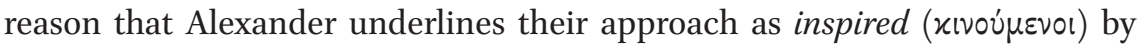
Aristotle, which may insinuate some sort of reservation.

This hedonistic argument is not the only 'Aristotelian' argument for hedonism in Alexander's report. More revealingly, he goes on to discuss another hedonistic argument, which is obviously based on more solid evidence in Aristotle (his account of pleasure in $E N$ VII and $\mathrm{x}$ ) than his tripartition of the ends adduced by the first group, in which the nature of pleasure does not take pride of place:

Verginius Rufus and before him Sosicrates said that each person desires

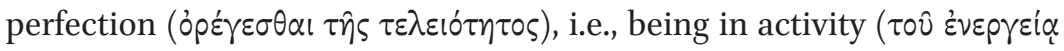

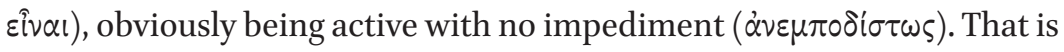
why he says that for us too being in activity is desirable, and this is being alive and the activities dependent on life, which are pleasant. For this kind of natural activity is, as long as it is unimpeded, pleasant. But for each thing its perfection is a good. [...] By desiring to be in activity, one would desire one's own proper perfection. And this is a good for each, so that we desire it. It is consistent for those who postulate that the primary

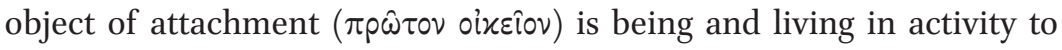

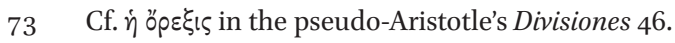

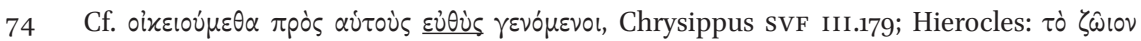

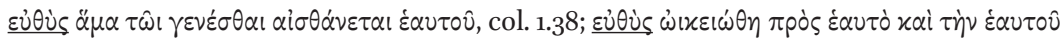

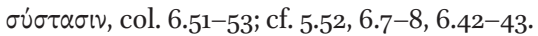

75 Top. 118b28; 105a27; EN 1104b31, 1105a1; cf. SE 102b16-18, [Div.] 46. It is remarkable that this classification of the good is also admitted by Alexander himself, see Fat.15.185.21-28, Mant. 174.17-24. Cf. Sharples 2004, 155 n. 526. 
say that the primary object of attachment and the good ( $\tau \dot{o} \alpha \gamma \alpha \theta \sigma^{\prime} v$ ) is pleasure.

Mant. $151 \cdot 3^{-1} 5^{2.1}, 3^{-6}$

At stake is obviously a hybrid account of Aristotle's understanding of pleasure. It is hybrid, not only because these hedonists, ${ }^{76}$ like the first group of Aristotelians, align the Stoic discourse on the proper object of desire with Aristotle's theories, but also because they blend Aristotle's accounts in $E N$ VII and $\mathrm{x}$ into a coherent foundation for their hedonistic view. Pleasure as a perfection is the key lesson from $E N \mathrm{x}$, whereas the association of pleasure with an unimpeded activity apparently stems from $E N$ vir. By identifying the unimpeded activity with the perfection (teleiotês) of the nature of a subject, these hedonists establish a close link between pleasure, goodness, and activity. Just like Alexander, they are not puzzled by the supervenience relation in $E N \mathrm{x}$, but are content with the vague affinity between pleasure and activity; it is thus also unclear in what sense pleasure and activity are identical with or different from each other. It is presumably in part for this reason that they have enough wiggle room to accommodate the accounts of both $E N$ VII and $\mathrm{x}$. In any case, it is not inconsistent if they, on the one hand, speak of the unimpeded energeia in $E N$ VII, and on the other argue for hedonism by drafting the theory of $E N \mathrm{x}$ as an ally when necessary. Although Alexander is unsatisfied with their hedonistic implication, their treatment of Aristotle's two accounts of pleasure is irreproachable insofar as it fits well into the way Aspasius, Alexander, and other ancient commentators combine the two books of Aristotle in their compatibilist readings.

\section{Alexander Reconsidered}

Alexander's criticism of the hedonists in the Mantissa appears less decisive than that in the $P E$. Either he has not found a proper way to meet the challenge from the Aristotelian hedonists (if this treatise was written earlier), or the Stoic framework of Mantissa $§ 17$ seems to constrain his argument, so that he cannot

76 It is not clear whether or in what sense Verginius Rufus and Sosicrates belong to the Peripatos. Verginius Rufus might be the consul of $63 \mathrm{AD}$ who was the guardian of the younger Pliny. Sosicrates, according to Lautner (1997:304-305), might either be Sosicrates from Rhodes, the author of Successions ( $\delta\llcorner\alpha \tau$ i $\beta \hat{\omega} \nu$ ) in DL 2.84, 6.80 and 7.163 or a student of Carneades mentioned in Philiodemus' Index Academicocum xxIV. 8. The former can be Peripatetic, while the latter might be an Academic. cf. Sharples 2004, 155 n.527; Falcon 2012, 155 . 
develop his criticism at length by providing his more 'authentic' interpretation of Aristotle. In the Mantissa, he launches his attack on the Aristotelians from a 'Stoic' point of view, namely by disclosing their failure to grasp what the end actually is. He finds fault with the first group of hedonists in that they do not distinguish between two kinds of ends, confusing goodness for someone with goodness without qualification (Mant. 151.27-29). After that, he applies a similar criticism to the second group, pointing out that they do not distinguish between the apparent good (= pleasure) and the true good (cf. 152.20-35). It is unexpected, however, that Alexander seems hesitant about whether this argument is sufficient to refute the second group of hedonists, perhaps because they appear to be able to gain more support from Aristotle's official account of pleasure. So he abruptly withdraws his criticism at $15^{2.35}$, and turns to another convoluted argument (152.35-153.27), the gist of which is unfortunately difficult to tease out. No matter how we assess this elusive shift, what is more significant for our purposes is to note that Alexander's 'new' argument seems to be an embryonic form of his central anti-hedonistic strategy in the $P E$.

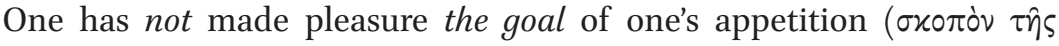

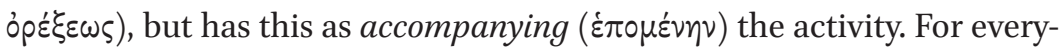
thing which is in accordance with nature is pleasant. It is not the case that, having first enjoyed pleasure, one then on this basis has appetition for that through which he enjoyed pleasure.

Mant. $153 \cdot 14-17^{77}$

Alexander distinguishes between the proper end and something that accompanies the end, that is equivalent to a distinction between the energeia as the end and pleasure as its concomitant. Based on this distinction, he replies to the hedonists that although all activities are pleasant if they are in accordance with nature, that does not mean that pleasure is thereby the reason or the end of one's appetite, because pleasure is only a concomitant of the activity. This argument, despite still being in a 'para-Stoic' fashion, accords in principle with the argument in the $P E$ based on the supervenience-relation between pleasure and activity.

In any case, Alexander's debate with the hedonists (especially with the second group in Mant. §17) seems to foreshadow the conflict between Alexander and the anonymous anti-hedonists in the PE. The hedonists in the Mantissa (Verginius Rufus and Sosicrates) and the hedonists in the $P E$ are in agreement that they champion the intrinsic connection of pleasure and activity based on

77 Trans. by Sharples 2004, my italics. 
their reading of Aristotle. If we recall the aforementioned distinction between the Extrinsic and Intrinsic Readings of the Aristotelian definition of pleasure in contemporary Aristotelian scholarship, then the debate between Alexander and the Aristotelian hedonists foreshadows the classical debate over Aristotle's pleasure as supervenience in contemporary academia. According to the hedonistic Aristotelians, the intrinsic relation between pleasure and activity means that as long as an activity is perfect, pleasure occurs naturally as integral to this activity, sharing its central properties. For Alexander, however, the link between activity and pleasure is external. Alexander underlines how the value of pleasure is determined by that of its corresponding activity, and ignores the reciprocal contribution of pleasure to the activity in question. He also emphasizes how pleasure can emerge indiscriminately from all kinds of activities, and is no more intimately bound up with the activity if it is unimpeded or in an excellent condition.

The discrepancy between Alexander and the 'hedonists' also extends to pain. Admittedly, both agree that pleasure is opposed to pain, and both use the mirroring method, trying to infer the properties of pain from its opposite pleasure. Nonetheless their findings are quite distinct. For the 'hedonists,' pain is connected with the incompleteness of activity, so that as long as an activity is bad, the corresponding pain occurs naturally. This also explains why shameful activity is not desirable. In this sense, pleasure and pain indicate respectively the properties of the activity they accompany as differentiating signs. By contrast, Alexander points out emphatically that 'pleasures supervene no less on shameful activities [than on noble ones]' (PE 145.20-21), ${ }^{78}$ which shows that, in his view, pleasure is neither immanent in perfect activities nor does it (even partly) constitute these activities. Accordingly, there is no intrinsic relation between pain and bad activities.

Alexander argues against both the intrinsic connection between pleasure and good activity and the causal contribution of pleasure to activity, because he believes that these relationships pave the path towards hedonism, a view from which any true Aristotelian should distance himself.

For it is not possible to say that nobility and pleasure are the same thing in the cases where they co-exist and exist at the same time as each other. For if their essence were the same, it would be necessary for them to be convertible with each other, so that everything that was noble would, in 
being noble, also possess the quality of being pleasant, and everything that was pleasant would simultaneously be both pleasant and noble.

$$
\text { PE } 145 \cdot 14-18^{79}
$$

In his view, the foundation of this hedonism is fragile because the hedonist point of view boils down to a dilemma from an Aristotelian point of view:

Either one must deny that certain pleasures supervene also on shameful actions, [saying that they supervene] only on noble ones; or else what is shameful will truly deserve to be chosen in the same way as what is noble, if it is the pleasure that they produce that is the cause of their being chosen.

PE $145 \cdot 5^{-8} 8^{80}$

The aporia Alexander raises is that either they think that pleasure supervenes only on noble activities, or that they must permit that shameful activities are also worth choosing. If they choose the first alternative, Alexander would object that this does not square with common sense; if they opt for the latter, they would fall into self-contradiction because they also explicitly reject the pursuit of shameful activity, albeit for different reasons (PE 145·31-33). Under meticulous scrutiny, however, the doctrine of these hedonists is not unable to meet Alexander's challenge.

In the debate with the hedonists, the criterion used by Alexander to distinguish between different kinds of activity is no doubt ethically oriented. So instead of predications of good and bad, he more frequently talks of noble (kalon) and shameful (aischron) activity. ${ }^{81}$ By contrast, although what is determined as the perfect activity in Aristotle is not independent of ethical connotation, the key aspect is predominantly functional in a broader sense. A perfect activity, according to Aristotle, is one in which the subject, its object, and their relation are all in an excellent state for carrying out their functions. ${ }^{82}$ Since both animals and the gods are included in Aristotle's account of pleasure, it

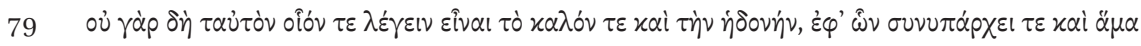

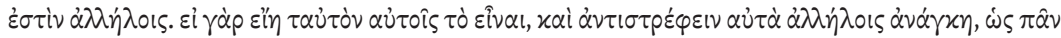

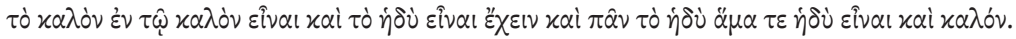

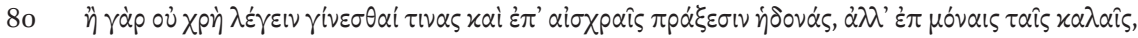

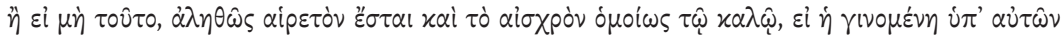

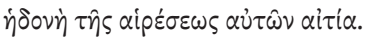

81 PE 127.16-18; 134. 20-22, 25-27; 138.10-11, 14-28; 139.3-14; 144.10-17; 144.33-145.11; 145.18-21, $23-24 ; 28-34 ; 146.1-7 ; 12-13$.

$82 \quad E N$ X.4.1174b14-23; 28-31. 
definitely demonstrates that the values in question are beyond moral good and evil. ${ }^{83}$ If we bear this aspect in mind, the hedonists are in fact not so helpless when confronted with the dilemma raised by Alexander. To be sure, they will not deny the empirical fact that pleasures are present not merely in noble activities but also in shameful ones. But they can doubt that this is what is meant by the so-called noble activity upon which pleasure supervenes. If the claim that pleasure supervenes merely upon the noble activity means that pure pleasures, namely the pleasures which are not mixed with any pain, must supervene upon the perfect activity and constitute this activity, the hedonists are willing to embrace this opinion without hesitation. And obviously, this kind of pleasure could not accompany shameful actions. But if the noble activity is understood in an ethical sense, they would reply that what they are chiefly concerned with is not limited to morality, but the overall function of a living organism or its part.

As we have seen, Alexander understands the supervenience relation between pleasure and activity as pleasure's being somehow a part of the activity or its end. ${ }^{84}$ But, presumably in order to avoid any hedonistic implication to which such characterizations might lead, he does not address these options again. In fact, his final doctrine is not even compatible with them. For it is inconceivable that pleasure, if it is a part or an end of an activity, is causally inert. Although Alexander bases his anti-hedonistic argument on Aristotle's official doctrine that pleasure supervenes upon activity, his epiphenomenalist reading of this theory renders him closer to Stoicism than he would be willing to acknowledge. For the classical anti-hedonistic strategy used by the Stoics, as Diogenes Laertius tells us, is to argue that pleasure is not the primary attachment, but a by-product (epigennema), ${ }^{85}$ a term derived from the verb epigignetai used by Aristotle for the so-called supervenience relation (cf. $E N \times 1174 b 33)$. It is thus conceivable that although Alexander purports to provide a faithful interpretation of Aristotle, his account would not persuade all of the Aristotelians, in particular those who are inclined to set up a close link between Aristotle and the hedonistic tradition. Theoretically considered, at least four elements in Alexander would be controversial. (1) The supervenience relation between

\footnotetext{
83 Cf. $E N$ vil.1.1145a25-27; 12.1153a30-31; b25-32; 14.1154b25-28; X.2.1173a1-5; 5.1176a5-9; 7.1177a23-24.

84 PE 127.10-13.

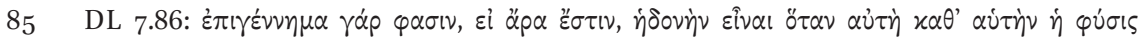

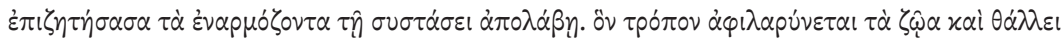
$\tau \dot{\alpha} \varphi v \tau \dot{\alpha}$. Cf. the anti-hedonistic argument of Cleanthes in SVF III 155. For a more sophisticated interpretation of the Stoic understanding of pleasure as epigennēma, in particular in Seneca, see McVane in this volume.
} 
pleasure and activity is evenly distributed in the sense that the supervenience of pleasure upon an excellent energeia does not enjoy any privilege in comparison with the supervenience of pleasure upon the energeiai that are bad or neutral. (2) Although good pleasure must derive from a good energeia, it is not conversely warranted that a good energeia must intrinsically entail a corresponding pleasure. (3) Pleasure and pain do not have any independent causal effect. (4) Since every concrete pleasure and pain obtains its evaluation respectively from the activities accompanied by them in opposed ways, the value of pleasure and pain as a whole is indeterminate. ${ }^{86}$

How would the other Aristotelians object to these theses? If Alexander accuses them of degenerating into Epicureanism, they could counter him by questioning whether his proposal dresses Aristotle up as a Stoic sage. No doubt, they must agree with Alexander that pleasure as a whole can be good or bad. But this does not mean that pleasure by its very nature is axiologically indeterminate. On the contrary, they would reply, one of Aristotle's primary concerns in his two accounts of pleasure is to defend the positive value of pleasure as such by appeal to the affinity between pleasure and good activity. Pleasure, in short, does not only necessarily supervene on a good activity, if there is no external hindrance, but also as its perfection causally completes this activity. ${ }^{87}$ For this reason, pleasure is for them good, even if not all pleasures are good.

To understand why Alexander's interpretation is in tension with Aristotle's account, it may be useful to take a glimpse at the debate between Aristotle and Eudoxus over the argument from pleasure as an additional good. Eudoxus argues that pleasure is the ultimate good because if pleasure is added to (prostithemenēn) something, it makes this thing more valuable (EN x.2.1172b23-34). A full explication of this argument and Aristotle's reply is beyond the scope of my survey. But if we pay attention to the subtle divergence between Aristotle and Eudoxus in their debate, we might better grasp why some Aristotelians would reject Alexander's extrinsic reading of pleasure. Aristotle's diagnosis of this argument is intriguing. He does not dismiss the phenomenon [claim?] that the addition of pleasure makes other things better, nor does he seem to be bothered by any hedonistic conclusion to be drawn from this premise. On the contrary, he complains that this argument is not 'hedonistic' enough in the sense that it cannot fulfill Eudoxus' initial purpose,

86 Although Alexander does not thus evaluate pleasure and pain as indifferent, his position is very close to this Stoic classification of pleasure and pain. Cf. Stobaeus II. 5a; $7 \mathrm{~b}$.

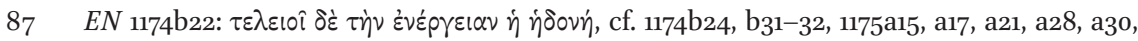
$1176 \mathrm{a} 26-29$. 
namely to prove that pleasure is the good or the best thing. For the most we can draw from the ability of pleasure to increase any other thing's good is a moderate thesis: i.e., pleasure is a good thing ( $E N$ X.2.1172b26-32). This diagnosis helps us better understand why Aristotle introduces supervenience to re-determine the relation between pleasure and activity. The intention of his proposal is actually to render their relation more intimate, which aims to show that pleasure, in the strict sense, is the good, by connecting and assimilating pleasure with perfect activity. ${ }^{88}$

To conclude then, I suggest that Alexander's approach in the $P E$ is considerably determined by his intention to resist the hedonistic implication his opponents draw from Aristotle's account of pleasure. The main target of Alexander's anti-hedonistic arguments is those who adopted a hedonistic reading of Aristotle's accounts of pleasure. To refute them, Alexander is forced to underrate the normative structure implied in the supervenience between pleasure and good activity, so that it is understandable that he denies any intrinsic link between pleasure and goodness. The cost of his reading is that pleasure, as something that is neither good nor bad in its own right, is deprived of any causal effect or normative standing. A merit is that this proposal can well explain why pleasures differ in kind according to Aristotle ( $E N$ 1173b28). In addition, it allows the positive evaluation of some pains, so that the Peripatetic demand of moderate emotions is kept consistent with Aristotle's doctrines about pleasure and pain. Moreover, it leads him to take the problem of pain more seriously than any other commentators on Aristotle. For although the neutralization of pain can accommodate an influential pain-friendly tradition, i.e., a tradition in which pain was taken as constitutive of the path to happiness, it seems at odds with Aristotle's use of the premise that pain is something bad in many dialectical arguments. To address this aporia, Alexander attempts to classify different kinds of pains, trying to figure out a way to explain in what sense Aristotle can take pain as bad even if there are pains which are good or neutral.

88 Alexander does not mention Eudoxus explicitly in the whole text of the Ethica Problemta. From his frequent quotations of the argument from contraries (Pr. §6, §7, §17), however, it is clear that he knows the Eudoxean arguments supporting hedonism very well (cf. Sharples 1990a, 31, n73). Unfortunately, he fails to notice the significance of the debate between Eudoxus and Aristotle over the argument from pleasure as an additional good. Otherwise he would have endeavored to distance his own concept of supervenience from Eudoxus' thesis in which pleasure functions as an additional good. 